\title{
Possible Selves: Restor(y)ing Wholeness Through Autobiographical Writing
}

\author{
Ellyn Lyle
}

\begin{abstract}
Education is a human endeavor, yet its research often prioritizes empirical knowledge while marginalizing human aspects of the educative experience. Creating space for self has the capacity to foster wholeness where there is disconnectedness and, therein, challenge academic conventions that prioritize dehumanization. Situated within post-qualitative inquiry and drawing on autobiography, I invite students to explore with me premises gleaned from Palmer's work on identity and integrity. While we explicitly seek to explore how including autobiographical tenets can overcome practices that limit integrated ways of knowing, we also implicitly seek to legitimate the element of selfhood in our education contexts.
\end{abstract}

\section{Exordium}

Education is a human endeavor and, as such, is informed by the intellectual, social, political, and emotional experiences of teachers and learners. Despite this obvious situatedness, education research continues to prioritize empirical knowledge while marginalizing the uniquely human aspects of the educative experience. Acknowledging the undeniable appeal of evidence as we seek to enrich knowledge, I maintain that something uniquely human is lost in the exclusion of the affective, intuitive, creative, perceptive, and critical aspects of learning. In seeking to address this marginalized humanness, I draw from Parker Palmer's scholarship on wholeness (1993, 1997, 1998, 2004, 2017) and turn to postqualitative inquiry where I find resonance with St. Pierre who found an entry point into scholarship by advancing writing as a way of knowing (Richardson \& St. Pierre, 2005). As her scholarship evolved, she began to challenge the very notions of conventional qualitative inquiry, concerned that it provides only a "container with well-identified categories into which researchers are expected to slot all aspects of their research projects so they are recognizable" (St. Pierre, 2017a, p. 1). Exacerbating its pushing to the periphery new ways of seeing, being, and sense-making, she argues, qualitative methodology has "become so formalized, systematized, and positivized" (p. 1) that it has succumbed to the very quantification and measurement it was invented to resist. She reminds us that predetermined methodsdriven approaches are simply "never enough for the too much of inquiry" (p. 5), and the challenge of post-qualitative inquiry is to make room for living - both beings and inquiry. Drawing on the work of Deleuze and Guattari (1980/1987), she insists that this is made possible by refusing to be bracketed by methodology in favor of living with theory as we navigate experience in real time. Embracing this unstructured relationship with inquiry opens us up to possible experience previously made inaccessible 
(St. Pierre, 2017b). Returning to her roots in writing, St. Pierre advocates for scholarship as academic essay because of its capacity for fluidity and agility.

This advocacy reminds me of Badley's work $(2016,2017)$ where he champions post-academic writing. Badley (2017) discusses traditional academic texts as embodying the failures of academics to embrace their humanity in favor of claiming impartiality and objectivity. In so doing, academia has created a legion of disembodied scholars and fragmented thinkers. Drawing on the habitus made popular by St. Pierre of issuing provocations, Badley (2017) asks, "how might we, as students, teachers, and researchers, switch away from producing sterile, voiceless academic prose toward creating scholarly writing that is warm, inviting and intensely personal?" (p. 3). Ultimately, he concludes this accessibility is supported best when it embraces the slipperiness of being human and takes on a storied form.

Situated, then, in post-qualitative inquiry and challenging the inaccessibility of traditional academic writing, I embrace story to explore pathways to wholeness in our teaching and learning lives. Unable to separate one from the other, I invite to join me here graduate students who self-identified as interested in the capacity of autobiography to support this wholeness. Without particular destination in mind, we consider how story can help us overcome the broken paradoxes (Palmer, 2017) that limit integrity in teaching and learning. In the spirit of post-qualitative inquiry, this exercise compels me to identify those assumptions or premises that undergird my thinking/writing/teaching, and I follow each of these premises with a provocation offered to graduate students so that they might share their experiences as they relate to restor(y)ing wholeness. They could choose to respond to any or all provocations and were not limited by word count or form. As a pedagogical commitment to creating space for individual voices, their responses stand independently and in their own rights without further interpretation or commentary.

\section{An Entry Point}

So conditioned am I to write academically, I find lately I bore even myself. My writing has come to feel formulaic, and I am increasingly absent. This acknowledgment led me to wonder what, in teaching and learning, leads to this distance from our own selves. In thinking about that question, I was flooded with memories about schooling moments where I was asked to break with parts of myself. These chasms, while painful, came to provide me with a backdrop against which to develop my teacher-self. I decided to think with theory through story about the role of autobiography in praxis development.

\section{Premise One: Teaching Is Autobiographical Work}

It has long been established that teaching and learning are autobiographical endeavors (Bochner, 1997; Bochner \& Ellis, 2016; Feldman, 2005). Despite historic criticisms, the inclusion of autobiography in our

practices is neither narcissistic nor egocentric. Being critically conscious of the embodied wholeness we bring to the classroom benefits both students and teachers (James, 2007; Lee, 2012; Palmer, 2017). 
Recalling how my own learning experiences sometimes left me feeling fragmented, I was determined to enter the school system as a teacher differently. I would make room for students' lived experiences in the classroom and work to find the balance that allowed school to be both relevant and respectful. Despite my good intentions, though, I found myself as a teacher inside the same education system that pained me when I was a student. Exhausted by the immense effort to create more meaningful learning spaces, I grew disengaged, then disconnected, and eventually deeply discontent. I left the K-12 system not quite four years after I began teaching, and I turned to writing to help me understand my experiences. In the privacy of my own journals, I was able to make sense of the brokenness and, in so doing, recognized it as residing in too little room for the elemental self in teaching and learning. I took two actions toward a course correct: I returned to graduate school to study the role of autobiographical narrative in practitioner development; and I accepted a job at a local potato processing plant as the resident teacher. In my new setting, I met adult learners everyday who had disengaged from formal schooling and, wanting to foster reengagement, I was careful not to reproduce hurtful practices. As both teacher and graduate student, it seemed appropriate for me to develop a research inquiry that would enable me to understand the experience of adults who had disengaged from schooling. Having personally struggled to reengage, I invited three individuals to share their stories with me. With their permission, and with the permission of the organization, I conceptualized and completed a thesis that used story to make central the role of self in teaching and learning.

The inclusion of autobiography in education allows us to interrogate self while locating self-study relationally across the various contexts within which we live and teach. As such, autobiography allows us to understand teaching and learning as grounded in personal history. Approaching inquiry from this perspective supports the development of critical reflexivity where impressions of self can be understood in terms of social contexts (Hickey, 2016). Extended slightly further, "autobiography is theory, [and] every theory is a fragment of autobiography" (Snowber \& Wiebe, 2009, p. 5). Now a Dean in a Faculty of Education, some 15 years after having established the adult learning centre in a processing plant, I wondered about the stories of my more recent students and if the inclusion of autobiography in their studies supports education that values lived experience. This curiosity became the first provocation offered to them for response.

Teaching, educating, and living are autobiographical journeys, and ignoring the value of experience in our students or ourselves constitutes an ethical injustice. Education is what we expect of ourselves, not what others say we can achieve. Including autobiography has changed me as a person, as a teacher, as a leader, as a father, and as a husband. Story has become a tool for consciousness. (Chris) 
The inclusion of self in graduate coursework allowed me to find a place for me in education. It helped me understand that education is an imperfect system, not that I am an imperfect student. Rather than feel burdened by my diverse learning needs, I learned to value them as an integral part of a rich educational environment. I have come to understand that diversity is a school's responsibility to value, not a student's problem to fix. As an educational leader, this new lens will inform my work. (Cindy)

Autobiography can provide a space in the classroom to value lived experience while encouraging an ethics of care. Stories bring meaning to our lives, so limiting ourselves to scientific knowledge limits our abilities to think critically and live creatively. (Brian)

\section{Premise Two: Good Teaching Is Inextricably Connected With Identity and Integrity}

As I continued to mature in my practice, my interest in the autobiographical tenets of teaching and learning led me to explore issues of identity. I encountered Parker Palmer's work (1993, 1997, 1998, 2004, 2017) and found immense pedagogical resonance. Palmer (2017), a teacher and story-teller himself, insists that "good teaching cannot be reduced to technique-[that] good teaching comes from the identity and integrity of the teacher" (p. 10). He describes identity as the evolving nexus of intersectionality and lived experience, and he says integrity is what wholeness we can find within that nexus as we continue to re-story who we are.

Having established at that local processing plant a strong and sustainable program that made central the role of self in teaching and learning, and having completed my master's degree, I decided to pursue doctoral studies. My area of interest involved the various contextual aspects of self we bring to profession and how these inform praxis. After the completion of my residency, I recognized that my research would be made more robust by once again considering theory in terms of practice, so I accepted an offer of employment with a global Human Resource firm as National Learning Manager. While I held this position, I led a team of advanced-degree educators in the development and facilitation of leadership, change, and organizational effectiveness programs for public- and private-sector employees. While working in this capacity, my graduate work again employed narrative strategies to theorize implications for praxis. Upon completion of my PhD, I joined the academy full time and have, since then, continued to advocate for the consideration of self in teaching and learning.

Several scholars discuss the significance of self in the educative experience (Cole \& Knowles, 1994; Elbaz, 1991; Ellis \& Flaherty, 1992; Hatt, 2006; Palmer, 1993, 1998, 2004, 2017; Van Manen, 1990; and Wheatley, 2009). While many theorists discuss this tenet in terms of inevitability, Palmer embraces it, insisting that to deny self not only limits learning, but also breeds disconnectedness. Palmer refers to disconnectedness as a form of disengagement that occurs when we experience feelings of detachment 
from our learning. In my reading of Palmer, I understand this detachment as occurring in any of three dimensions: spiritual/physical (when a learner feels estranged from the educative experience but remains physically within the learning environment); individual/communal (when learners who continue to seek paths to connectedness search for contexts that promote and enable it); and personal/public (when learners share personal experiences to encourage others who are feeling disconnected). He suggests that the dimensions are progressive stages of disconnection and offers critical reflection as a support strategy. Understanding reflection as after and individual and reflexivity as ongoing and relational (Lyle, 2017), I suggest extending Palmer's work to include reflexivity as a strategy that can disrupt disconnection and preclude progression to more advanced stages of fragmentation. This supposition led me to a second provocation: that making room for self in schooling practices strengthens people, individually and collectively. I returned to my students once more to gain a sense of their perspective on this notion.

When we reflect on the teachers who made a difference in our lives, we picture the ones we trusted, respected, and loved. These teachers were not feared-they were adored; students eagerly waited to be in their classes, not necessarily because they were breaking achievement records, but because they were authentic. (Tina)

When we speak of identity, we must look at all the forces in one's life that merge to constitute who you are. I identify as a biracial First Nations person, with two different family heritages, raised in a multicultural, but predominantly First Nations community. I remember the significant figures who helped me along the way and those who left me scarred, but stronger. I can remember the racism, challenges, and other difficulties throughout my life that taught me valuable lessons. I also remember the point in my life where I had to make the decision to leave the community or risk descending into an abyss that I may never climb out of. My integrity has been shaped by these experiences. By making space for self, we remove the cultural barriers of Silence, Individualism, and Secrecy, thereby strengthening people individually and collectively. If we do not make room for ourselves, then we become fragmented not knowing who we really are. (Brian)

I need to know who I am before I can help someone become who they want to be. It is difficult to pretend to be someone or something you aren't. One day in class a student asked me about my family and, when I acknowledged a struggle there, the student started to cry. Having a student shed a tear over my family's difficulties taught me that students cared about me, just as I do about them. Sharing ourselves strengthens our abilities to be credible sources of support for the students. (Lisa) 


\section{Premise Three: We Create Identity Through Story}

Several scholars have taken the position that we cannot know others if we do not know our selves and, without these inherent understandings, our capacities to teach and learn are significantly diminished (Eakin, 2008; Lee, 2012; Palmer, 1998, 2017; Whyte, 2001). If we are to accept this position and wish to remain meaningfully engaged with teaching and learning, it follows that we must pursue self-knowledge to excel in our professional practices. The use of story to facilitate self-knowledge gained traction in education research in the 1990s (Bruner 1986, 1987, 1990; Casey, 1993, Connelly \& Clandinin, 1999; McAdams, 1993). Since then, story has continued to provide a valuable lens for teacher self-study, a lens through which we can view the content and context of our work.

Having left behind learning and development in the private sector for the allure of the academy, I learned quickly that traditional academe was built on an old chassis of privilege and driven by rank. Because professors tended to work within their own areas of expertise, feelings of alienation and disconnection were normalized components of promotion and tenure. In the solitary pursuit of these coveted achievements, a faculty member's value was often determined by grant monies she brought in and publications she put out. These being the currencies required to advance, teaching often felt secondary. While I had deep and broad respect for the work required to advance scholarship, I was troubled by recurring complaints that the professorial life would be much enriched without the burden of teaching. Recalling my previous experiences in education systems that marginalized, I began to consider other career trajectories. About this time, I was invited to an emerging privately funded, non-tenure-based university to consider a core faculty role. Having grown up in the publicly funded K-12 and postsecondary systems, I had internalized the suspicion of private institutions. Curious, despite skepticism, I accepted the invitation. Greeted by the president, the Vice President (Academic), and the Faculty Dean, I was impressed by the seemingly flat organizational structure and the resulting approachability. Upon closer inspection, this translated into a culture of collaboration and accessibility. This culture was not only evident among the teaching, administrative, and support staff; it was also intuitively characteristic of the school's commitment to the student learning experience. While the education faculty was newly established and still emerging, it was evident that the core values had at their centre the best interests of students. Invited to join this school, I was fortunate to grow with it, informing its development. In the almost six years I've been in this setting, I remain gratified by management's commitment to listening to students and its agility in responding to change. It has created critically conscious graduates and responsive faculty and administrators.

As I think within my current context and story it in live time, I realize that the potential born of stories is vast. They have been noted to help us do at least four things: overcome fear (Harkins, Forrest, \& Keener, 2009; Palmer, 2017); articulate our realities (Bochner, 2014; Eakin, 2008; Goodall, 2000, 2008; Holman Jones, Adams, \& Ellis, 2013; Palmer, 2017); mobilize change (Pelias, 2015; Quintero \& Rummel, 2015); and reveal our possibilities to ourselves (Bochner, 2014; Eakin, 2008; Goodall, 2000, 2008; Holman Jones et al., 2013; Palmer, 2017; Pelias, 2015; Poulos, 2013). Realizing the potential of stories 
begins with overcoming fear. Palmer tells us that this fear is most evident in our refusal to tell our vulnerable stories. He says we seek safety in abstraction and steer conversations toward opinions and ideas, rather than our nuanced lives. This practice, he says, is encouraged by an academic culture that insists the more abstract our speech, the more likely we are to encounter universal truths but, in reality, the reverse is the result: the deeper in abstraction we dwell, the more disconnected we feel. Harkins and colleagues (2009) push this a bit farther and say that we can examine our stories for the fears that shape our current research and teaching practices. These stories need not be elaborate works of fiction or nonfiction. Telling a story honestly and unapologetically can contribute powerfully to our insights while acting as a pedagogical strategy (Harkins et al., 2009; Palmer, 2017).

Stories are also useful for uncovering and communicating the realities of who we are. They are tools central to sense-making and fostering a coherent sense of identity. They can connect us to ourselves, others, society, and our multiple varied contexts as well as provide strong points of divergence through which we come to know self more deeply. They can help us overcome the narrow conceptualizations of curriculum and, through the integration of lived and living experiences, help students and teachers locate themselves in place and time (Quintero \& Rummel, 2015). In this way, story provides a gateway to understanding the political nature of the educative experience. In addition to exposing the multiple and often conflicting tenets of teaching, stories can mobilize these experiences to encourage change. These become the stories for imagining both the world's potential and our possible selves (Pelias, 2015; Poulos, 2013). In pausing to consider how lived experience can foster respect for socially responsive ways of being, I found my third provocation and sought student insights once again.

Having lived experiences is not enough. As leaders, it is important to understand how our assumptions, opinions, and purposes influence how we think and act. To have a positive influence on students, we must be conscious of how lived experiences can affect us both positively and negatively. As educators, we can likely recall those teachers who inspired us or who left an indelible impression on us. For me, it my Grade 6 teacher-he was a small man, who had a hunched back, but he was an excellent teacher and very supportive and understanding of everything I did. There were also other teachers who I admired and whose methods I've incorporated into my teaching. While they were all different, they have one thing in common - they all had good hearts. In our culture, there is a term for this called Um Go'oti. Having a good heart is a way of being, an important one as students can detect impostors. (Brian)

In January, I started my graduate degree. I had not been a student in more than 20 years. It was very overwhelming. I found my courses challenging and, at times, I felt like I was drowning and writing in circles. Hearing stories of my professor's learning journey made me realize that I have stories of my own worth sharing and they, too, might help others learn. Instead of seeing a professor with rigid views of theories, I saw a person. A person with stories. 
A person who can reflect on her life and use it to move forward. A person just like me, working to improve herself and some aspect of the world we live in. (Lisa)

As I critically reflected on my career, I realized that life taught me to walk my own path and to do what was right by my own values. But I had deviated from that path by walking too long in the shoes that had been assigned to me. I realized I had betrayed myself and, in turn, had damaged others in a blinded conviction to follow the practices that were set out for me, which inevitably where the same practices that turned on me when it suited the establishment. Uncovering this through story unlocked many realizations and engaged me in my work once again more deeply than ever before. I began to walk in line with my values, my own beliefs, which allowed me to learn from my own experiences and to retell stories of my life. (Chris)

\section{Premise Four: We Foster Integrity Through Problematizing Broken Paradoxes}

In grappling to understand how the inclusion of self and self-in-relation might mitigate disconnectedness, I found resonance in Palmer's (2017) discussion of broken paradoxes. He says that education seems filled with inconsistencies because of our tendency to think in polarities. In positioning parts of self and experience as dichotomous, we create divisiveness: head/heart; facts/feelings; theory/practice; and personal/professional. He argues that we need to "think the world together by means of paradox" (p. 91) if we want lives of integrity. He reminds us that the current culture of disconnection is driven partly by fear and partly by the Western notion that disconnection is a virtue. In discussing the element of fear, he implores us to "resist the perverse draw of the disconnected life" (p. 36).

I've repeatedly found myself on paths that led me to disconnectedness, fragmentation, even rupture. Sometimes I ended up on these routes because I was not paying attention to where I was headed. Sometimes I chose them deliberately (mis)guided by idealistic notions that they could lead to places other than where they did. Regardless of the choices that put me on these roads, I've found that, once there, I am the only one who can help me find my way back. That way back begins by seeking to untangle any incongruence between what I value and how I live. This process is assisted by finding meditative spaces where I can visit myself uninterrupted and grapple with issues that reveal themselves. I've come to understand this process as renegotiating identity and reconstructing a self that might be feeling disassembled. I am in such a space now, wondering about the chasms we craft in teaching and learning. (Re)turning to story, I seek to understand my essential (albeit ever-evolving) self, my professional practice, and my potential to contribute. Currently curled up in my big leather chair at my summer home-come-winter-writing-retreat, watching the bay now too cold to buoy me, I feel myself reconnecting with every iteration of myself that I have ever been and all those me's I've not yet grown into. 
I recall reading in my youth about the red thread of fate and wonder once again if my soul connection is to place and the ground it accords to cultivate new understandings. I wonder, too, if we leverage our best understandings from these places of wholeness, can we create a social movement to revitalize wholeness in education. This possibility became the final provocation shared with the graduate students who so generously agreed to accompany me as we think with theory through story.

I have had the opportunity to work in a variety of schools in various capacities in elementary, middle, and high school settings. The schools that left me feeling eager to wake and get to work were the schools that worked together. These schools were community-based, offering a sense of home away from home. We were encouraged to open ourselves to sharing, collaborating, and experiencing education in ways that might change our old practices and open us up to new ones. We were challenged as educators to be innovators, not programmers. We were called to find our passion and share this with our students to inspire the next generation of great thinkers. (Tina)

I have walked disconnected at many times in my life-following what was expected of me as an employee, as a teacher, as a husband, and as a father. Many times, I have been lost in those journeys, despite following the normative practices of socially identified roles. I failed to connect the reasons for my personal state of mind with the realities of my navigation, the disconnectedness in myself with my practices, separating my own compass from the external GPS of the world. This exploratory process taught me the importance of taking time to evaluate the underpinnings that formulate my reactions - to pause when something doesn't sit well, and to speak when I might be expected to be silent. Examining the sources of silence in myself has allowed me to make space to break the silence with others. Where silence previously permeated a problem, I now open the silence into a safe place for examining understanding for others and myself. I expose myself to vulnerability. I admit my impostership openly, and I sleep well at night. (Chris)

One of my favourite movie lines is from Shall We Dance with Richard Gere and Susan Sarandon. After a tumultuous period in their marriage, Gere's character questioned the purpose of marriage, to which Sarandon's character paused and stated, "... because we need a witness to our lives" [Fields et al., 2004]. I think this requirement is true for everyone, but I think we find witnesses in different ways. As an introvert, for example, I find witnesses through writing. I want others to know of the experiences I have had, but I shy away from activities that single me out as the centre of attention. Rather than verbally tell a story, I feel compelled to write it. In this regard, I am a storyteller and perhaps an unconventional scholar. Ellyn, through her encouragement of self, taught me to tell a story within the confines of an academic paper. Rather than view the writing as a chore, I was motivated to reflect in hopes of connecting with others. This writing is my best, but it is not always viewed as valuable. If we could hear all voices, and respect all methods to share those voices, we could revolutionize education. (Cindy) 


\section{Possible Selves}

Teaching is vulnerable work because sharing self is a prerequisite condition of meaningful connection to others. As rational beings who are often conditioned to disregard that which makes us uniquely human, we hesitate to make space for this openness in teaching and learning. In denying our humanness, though, we limit our abilities to learn. As we stand at the convergence of self and the subjects with whom and which we engage, it can feel like a daunting task to weave connectedness. Yet, we must. The alternative erodes our humanity and diminishes both personal and professional integrity. Increasingly, scholars and practitioners alike turn to the inclusion of autobiographical elements, most frequently accessed through story, to promote wholeness, both individually and collectively. For those of us bored with academic conventions and maybe even of ourselves, post-qualitative inquiry provides an avenue through which we put aside the recipe and experiment with the ingredients. It is through this experimentation that we chance an encounter with what Markus and Nurius (1986) name our possible selves.

\section{Acknowledgment}

I want to extend sincere gratitude to the following educators who, individually and collectively, seek to foster wholeness where there is disconnectedness and, in so doing, strive to legitimate the element of selfhood in education contexts: Cindy Cook, Lisa Ellis, Chris Keyser, Tina McDonald, and Brian Muldon.

\section{Author Note}

The students were selected based on their self-identified interest and, after fulsome disclosure as a part

of ethics review, each provided informed consent with the expressed desire to participate in the inquiry by responding to the provocations as presented.

\section{References}

Badley, G. (2016). Composing academic identities: Stories that matter. Qualitative Inquiry, 22, 377-385.

Badley, G. (2017). Post-academic writing: Human writing for human readers. Qualitative Inquiry, 0, 00, $1-12$.

Bochner, A. (1997). It's about time: Narrative and the divided self. Qualitative Inquiry, 3, 4, 418-438.

Bochner, A. (2014). Coming to narrative: A personal history of paradigm change in the human sciences. Walnut Creek, CA: Left Coast Press.

Bochner, A., \& Ellis, C. (2016). Evocative autoethnography: Writing life and telling stories. New York, NY: Taylor and Francis.

Bruner, J. (1986). Actual minds, possible worlds. Cambridge, MA: Harvard University Press. 
Bruner, J. (1987). Life as narrative. Social Research, 54, 13-32.

Bruner, J. (1990). Acts of meaning. Cambridge, MA: Harvard University Press.

Casey, K. (1993). I answer with my life: Life histories of women teachers working for social change. New York, NY: Routledge.

Cole, A. L. \& Knowles, J. G. (1994). Through preservice teachers' eyes. New York, NY: Merrill.

Connelly, M., \& Clandinin, J. (1999). Shaping a professional identity: Stories of educational practice. New York, NY: Teachers College Press.

Deleuze, G., \& Guattari, F. (1987). A thousand plateaus: Capitalism and schizophrenia (B. Massumi, Trans.). Minneapolis: University of Minnesota Press. (Original work published 1980)

Eakin, P. (2008). Living autobiographically: How we create identity in narrative. Ithaca, NY: Cornell University Press.

Elbaz, F. (1991). Research on teachers' knowledge: The evolution of discourse. Journal of Curriculum Studies, 23, 1-19.

Ellis, C., \& Flaherty, M.G. (1992). Investigating subjectivity: Research on lived experience. Newbury Park, CA: Sage.

Feldman, P. (2005). Self-study dilemmas and delights of professional learning: A narrative perspective. English Teaching, 4, 2, 46.

Fields, S. (Producer), Weinstein, B. (Producer), Weinstein, H. (Producer), Tyler, J. (Producer), Wells, A. (Writer), Suo, M. (Writer, original screenplay), \& Chelsom, P. (Director). (2004). Shall we dance [Motion picture]. United States: Miramax Films.

Goodall, H. L., Jr. (2000). Writing the new ethnography. Walnut Creek, CA: AltaMira.

Goodall, H. L., Jr. (2008). Writing qualitative inquiry: Self, stories, and academic life. Walnut Creek, CA: Left Coast Press.

Harkins, M-J., Forrest, M., \& Keener, T. (2009). Room for fear: Using our own personal stories in teacher education. Journal of Teaching and Learning, 6, 1, 15-23.

Hatt, B. (2006). Heart in teaching: Attending the pathic: An inquiry into the pedagogical significance of educators' lived experiences of heart in teaching (Order No. NR40432). Available from Education Database. (304958729).

Hickey, A. (2016). The critical aesthetic: Living a critical ethnography of the everyday. In S. Steinberg \& G. Cannella (Eds.), Critical qualitative research reader (pp. 166-181). New York, NY: Peter Lang.

Holman Jones, S., Adams, T., \& Ellis, C. (Eds.). (2013). Handbook of autoethnography. Walnut Creek, CA: Left Coast Press.

James, J. (2007). Autobiographical inquiry, teacher education, and (the possibility of) social justice. Journal of Curriculum and Pedagogy, 4, 2, 161-175.

Lee, S. (2012). Knowing myself to know others: Preparing preservice teachers for diversity through multicultural autobiography. Multicultural Education, 20, 1, 38-41. 
Lyle, E. (2017). Of books, barns, and boardrooms: Exploring praxis through reflexive inquiry (2nd ed.). Rotterdam, NL: Sense Publishers.

Markus, H., \& Nurius, P. (1986). Possible selves. American Psychologist, 41, 954-956.

McAdams, D. (1993) The stories we live by: Personal myths and the making of the self. New York, NY: Morrow.

Palmer, P. (1993). To know as we are known. San Francisco, CA: Harper Collins.

Palmer, P. (1997). The heart of a teacher: Identity and integrity in teaching. Change, 29, 6, 14-21.

Palmer, P. (1998). The courage to teach. San Francisco, CA: Jossey-Bass.

Palmer, P. (2004). A hidden wholeness: The journey toward an undivided life. San Francisco, CA: Jossey-Bass.

Palmer, P. (2017). The courage to teach. San Francisco, CA: Jossey-Bass.

Pelias, R. (2015). A story located in "shoulds": Toward a productive future for qualitative inquiry. Qualitative Inquiry, 21, 7, 609-611.

Poulos, C. (2013). Writing my way through memory, autoethnography, identity, hope. In S. Holman Jones, T. Adams, \& C. Ellis (Eds.), Handbook of autoethnography (pp. 465-477). Walnut Creek, CA: Left Coast Press.

Quintero, E., \& Rummel, M. (2015). Storying a path to our future: Artful thinking, learning, teaching and research. New York, NY: Peter Lang.

Richardson, L., \& St. Pierre, E. (2005). Writing: A method of inquiry. In N. K. Denzin \& Y. S. Lincoln (Eds.), Handbook of qualitative research (3rd ed., pp. 959-978). Thousand Oaks, CA: SAGE.

Snowber, C., \& Wiebe, S. (2009). In praise of the vulnerable: A poetic and autobiographical response to Salvio's abundant Sexton. Journal of the American Association for the Advancement of Curriculum Studies, 5, 1, 1-18.

St. Pierre, E. (2017a). Writing post-qualitative inquiry. Qualitative Inquiry, 0, 00, 1-6.

St. Pierre, E. (2017b). Haecceity: Laying out a plane for post qualitative inquiry. Qualitative Inquiry, 23, 9, 686-698.

Van Manen, M. (1990). Researching lived experience: Human science for an action sensitive pedagogy. New York, NY: State University of New York.

Wheatley, M. (2009). Turning to one another: Simple conversations to restore hope to the future. San Francisco, CA: Berrett-Koehler.

Whyte, D. (2001). Crossing the unknown sea: Work as a pilgrimage of identity. New York, NY: Riverhead Books. 


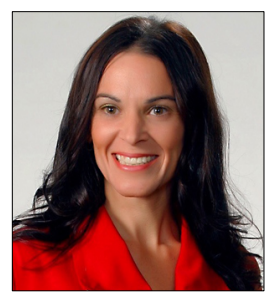

Ellyn Lyle has a longstanding background in innovative education practices, ranging from traditional classrooms to workplace and community partnerships, and technologically supported learning. In all these contexts, she has remained intensely interested in supporting the development of students and teachers as they contribute to socially equitable and sustainable programs. Ellyn holds a PhD in Education and has been teaching in university since 2010. She is currently Dean of the Faculty of Education at Yorkville University. The use of critical methodologies shapes explorations within the following areas: praxis; teaching and learning as lived experience; issues of identity; reflexive inquiry; narrative inquiry; and education for social justice. 
Ellyn Lyle

270 | LEARNing Landscapes | Spring 2018, Vol. 11 No. 2 